\title{
WestVirginiaUniversity
} THE RESEARCH REPOSITORY @ WVU

Graduate Theses, Dissertations, and Problem Reports

2016

\section{Oversized Load}

\author{
Kaitlyn Noel Hunter
}

Follow this and additional works at: https://researchrepository.wvu.edu/etd

\section{Recommended Citation}

Hunter, Kaitlyn Noel, "Oversized Load" (2016). Graduate Theses, Dissertations, and Problem Reports. 5842.

https://researchrepository.wvu.edu/etd/5842

This Thesis is protected by copyright and/or related rights. It has been brought to you by the The Research Repository @ WVU with permission from the rights-holder(s). You are free to use this Thesis in any way that is permitted by the copyright and related rights legislation that applies to your use. For other uses you must obtain permission from the rights-holder(s) directly, unless additional rights are indicated by a Creative Commons license in the record and/ or on the work itself. This Thesis has been accepted for inclusion in WVU Graduate Theses, Dissertations, and Problem Reports collection by an authorized administrator of The Research Repository @ WVU. For more information, please contact researchrepository@mail.wvu.edu. 
Oversized Load

Kaitlyn Noel Hunter

\begin{abstract}
Thesis submitted to the College of Creative Arts at Virginia University

In partial fulfillment of the requirements for the degree of
\end{abstract}

\author{
Master of Fine Arts In \\ Sculpture
Dylan Collin, Chair
Joseph Lupo
Jason Lee
Alison Helm

Division of Art

Morgantown, West Virginia

2016

Keywords: Art, Fine Art, Art History, Monsters, Perception, Body Politics

Copyright 2016 Kaitlyn Hunter 


\section{ABSTRACT \\ Oversized load \\ Kaitlyn Hunter}

This paper explores the research, artwork and processes that culminated in the "Oversized Load" Master Of Fine Arts thesis exhibition. I am examining the similarities between fear and perception of fictionalized monsters and how we label each other as humans. The fundamental question being, at what point does someone become the "other"? I look at both otherness and the grotesque in the context of body image. Both ostracization and cultural stigma are initiated by social shame. I see monsters as the physical manifestation of that shame. These feelings are closely tied to socially constructed gender norms and standards of beauty. This thesis discusses the analogy between monster mythology and contemporary body politics. It's those ideas that thread together the conceptual underpinnings and research of the "Oversized Load" exhibition. 


\section{ACKNOWLEDGMENTS}

First and foremost, I offer my sincerest gratitude to the University of West Virginia's College of Creative Arts for their academic and financial support for my Master thesis studies. Over the last three years I have been given the opportunity to pursue both my academic endeavors and gain invaluable teaching experience. Thank you to my graduate committee, Professors Jason Lee, Dylan Collins, Joseph Lupo and Alison Helm. This MFA research, artwork and thesis would not have been possible without their guidance, support, and encouragement. I appreciate all you have done for me.

Specifically, the sculpture program here has afforded me many wonderful opportunities. Being nominated by Professors Collins and Lee for the 2014 International Sculpture Centers (ISC) Outstanding Student Achievement Award was awesome and actually being chosen as a recipient was absolutely amazing. This recognition will forever help open doors to future possibilities. Somewhat later Dylan saw a call for entries for Disturbing Bodies, Disturbing Narratives and sent me the information for a digital exhibition. A member of the submission board was an ISC award recipient and invited me to New York to be part of a CAA panel. Walking through Times Square wearing one of my sculptures is honestly the coolest thing I've ever had the opportunity to do.

Thank you, Professor Lupo, for cultivating such an amazing community in your classroom. I really found my people in the printmaking tribe. It really means a lot that you all allowed such a messy sculpture kid into your fold. I would not have survived graduate school without Leslie's limitless love and Jake's unwavering friendship.

There are so many people who have influenced and supported me throughout this journey; my undergraduate professor, Duncan Hewitt and my friend, Karissa. I would also like to thank 
the maintenance staff that is the unsung heroes of the Creative Arts Center, specifically Ms. Maxine who always offers kind words, support and creative solutions to late-night disasters. There are so many amazing people who donated their time and skills to make this MFA show happen; Jake, Bridget, Oliver, Lindsay, Tessa, Kari, Heather, Andrea, Lydia, Allison and others. Most importantly, I must express my profound gratitude to my mother, Cathy Hunter, who has been an unyielding support and advocate throughout my academic exploration. As a student with multiple learning disabilities, this journey has never been easy. I'm so lucky to have such a supportive family. Love is driving down an interstate with a twelve-foot, fabric sculpture strapped to the roof of a minivan. My mother has instilled in me that we are not defined by our difficulties; anything is possible if you work hard enough. 


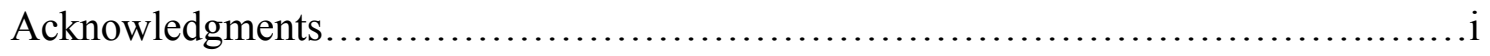

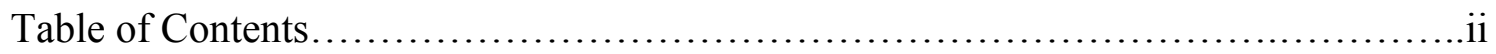

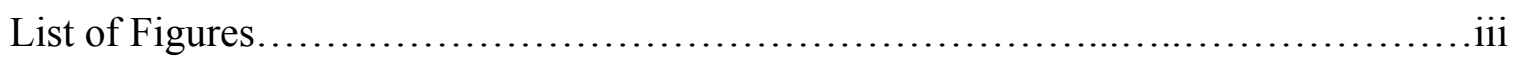

Introduction: Perception, Body Image and Monsters................................

Exhibition Overview: Immersive Installation.......................................2

Oversized Load: The literal \& Conceptual..........................................

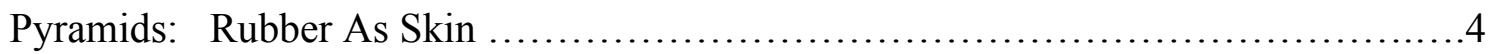

Monuments \& Self Concept.......................................... 5

Fun Fur................................................................

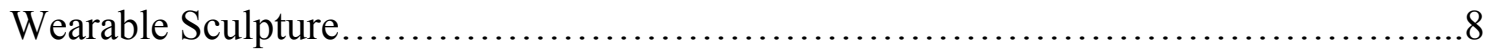

Character Building: Body Representations and Symbolism..........................9

Photography: Sculpture Display..................................................11

Performance: Models \& Theater................................................... 13

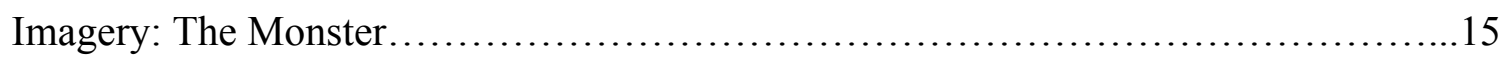

Two Dimensional: Influences...................................................

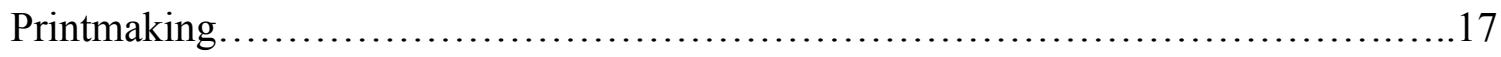

Reception: Myth \& Gluttony ...................................................... 19

Monster Masks.............................................................

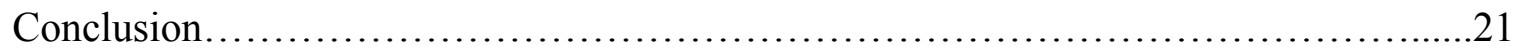

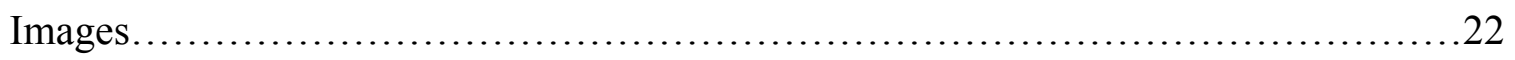

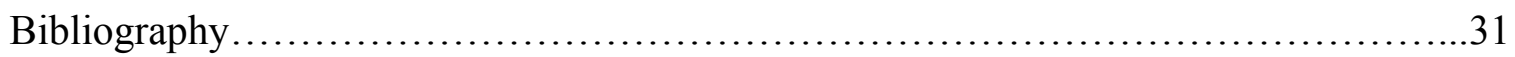


List of Figures

Figure 1: External wall of the Paul Mesaros Gallery

Figure 2: All The Sweet Nothings

Figure 3: Lee Bontecou, Untitled

Figure 4: Dr. Seuss' illustrations of Truffula Trees, Lorax

Figure 5: I'll Show You a Gorgon

Figure 6: Professional Enough

Figure 7: Not Everyone Gets To Be Pretty

Figure 8: I Can't Help the Way I Feel

Figure 9: Nick Cave, Sound Suit

Figure 10: Cindy Sherman, Untitled \#420

Figure 11: Monster Stickers

Figure 12: Nickelodeon, AHH REAL MONSTERS, 1994

Figure 13: Odilon Redon, The Cyclops

Figure 14: Couch Potatoes

Figure 15: Yayoi Kusama, Accumulation

Figure 16 Jessica Jackson, Settee 


\section{Introduction: Perception, Body Image and Monsters}

There is an inherent discourse between an individual's perception of themselves and society's perception of the individual. Ostracism and cultural stigma are initiated by social shame. The concepts of identity and perception are an important commonality throughout my work. It is within the context of "self" that I am investigating the other. I see the combination of the grotesque and the evolution of monster mythology as the physical manifestation of shame. In storytelling, monsters are used as a cautionary device to foreshadow the repercussions of undesirable behaviors or traits. Monsters rarely perceive themselves as such, because it is always a label given by collective social fear. I see a direct correlation between the fear and perception of fictionalized monsters and how we label each other as humans.

My work examines the fundamental boundary of the "us and them" mentality. Like monsters, "them" is situational and based on perception. Visually, I am exploring the relationship between human empathy and the superficiality of appearance in the context of what makes monsters monstrous. When examining the history of monster representation in film, a major thematic concurrence in werewolf lore is the iconic moment of transformation. This is seen in Hollywood's first mainstream werewolf film, Werewolf of London (1935) all the way through to The Howling (1981). Whether it's classical horror or current fantasy based movies such as Harry Potter and The Prisoner of Azkaban (2004) this moment is continuously represented. Unlike other iconic monsters, the werewolf has the privilege of passing at times as a typical human. They evoke empathy because they are often portrayed as having a conscience separate from the monster within. What makes that physical transformation so emotionally captivating is that moment of realization in every werewolf movie when a seemingly normal person looks down at his or her mutating hands and realizes they have become a monster.

The comprehension of social self-awareness, in regards to our own bodies, is essentially that same movement. There is a very short time in our young lives when we see our bodies as purely functional. Shapes and sizes carry no associations. They are only literal descriptions. However there is a dramatic shift in consciousness when we become aware of the social ramifications of our physical appearance especially in comparison to contemporary standards of beauty. As a child, the realization of fat being more than a description was like transforming into a werewolf. Though physically things didn't change, my whole self-concept shifted and for the 
first time I looked at my body and thought "ugly". The core of this work examines these personal inadequacies in the face of social standards, mainly the unshakable notion that as a morbidly obese individual, I am fundamentally failing at being a human on most levels. It is the merging of monster mythology and contemporary "body" politics that thread together the conceptual underpinnings of all the various mediums of the "Oversized Load" exhibition.

\section{Exhibition Overview: Immersive Installation}

Aesthetically, I am drawn to large, fleshy, bulbous forms. I am fascinated with the spectacle of abstracted bodies and how those forms function in space. As an artist I view myself as a world builder. I approached this installation with the goal of constructing an immersive installation. Drawing inspiration from freak show attractions, I created a series of wearable sculptures and monstrous characters to literally put on display inside the gallery, not unlike historical celebrities such as the Hottentot Venus and Lobster Claw boy. Formally this work is composed of a conglomeration of artistic processes. Silk-screening, welding, sewing, performance and photography all intersect together to create an interactive gallery experience. Overall, the work merges together a playful sensibility with heavy themes of body image to create a dark sort of whimsy.

In regards to the work, the exhibition is composed three major elements. First, there is an installation of tall pyramid structures sitting in the upper center of the gallery. As the viewer walks into the space they are at eye level with the hairy tops of these structures. Walking down the curved ramp the viewer then enters into a collection of pyramids, becoming confronted with the taller stature of these objects. Either side of the gallery is lined with five large framed photographs of wearable sculptures. In the back right corner there is an installation pile encompassing a blow up couch and hundreds of handmade pillows. The final element is four large monster cut outs protruding from the purple wall at the back of the room. Though lighting in the gallery is dark, the gallery itself is full of brightly colored work.

One of the major questions asked by my committee was "When do you divorce yourself from the expectations of the gallery? Also, how do you maintain traditions of display versus larger goals of finding specific, idiosyncratic means of presentation?" Similar to sideshow attractions, there was a necessity for the gallery to be physically part of the spectacle. It was important for 
me to externalize the feeling of walking into a different "world." Visually, I draw a lot from iconic freak show personalities and their infamous celebrity status. In researching freak shows and circuses I become enamored with not just the performers, but also the total atmospheric quality of the experience. Even the structures that house these enormities and spectacles have their own visual history. ${ }^{1}$ These theaters of curiosity have always shrouded its inhabitants while simultaneously drawing the attention of the masses. This is why I decided to wrap the outside of the gallery in "Oversized Load" paper.

\section{Oversized Load: The literal \& Conceptual}

There is something very human about the lumbering procession of an oversized load and how what it is really bearing is radical isolation. Because the signs are stating such an obvious visual fact, the warning label seems comically redundant. I am interested in the relationship of this phrase coupled with more ambiguous and conflicting forms. Oversized load has multiple meanings and functions as both a text and a pattern. In transportation, an oversized load is a load that exceeds the standard legal size or weight limits of specific roads. This term also applies to the vehicles themselves and their per axle weight limit. ${ }^{2}$ I use the repetition of the text as a visual transition between the silk-screened monsters and the wearable pieces. The term "oversized load" encompasses the core narrative of the work. It is referencing both the physicality of obesity and its perpetual emotional burden. Typically in the everyday world this phrase is seen as a warning to other motorists. It is a sign that the oversized vehicle inhabits and exists outside of the mainstream, with flag bearing cars and flashing lights further isolating them.

When looking at the gallery as a whole, I felt that it was imperative to activate the external wall of the Paul Mesaros Gallery (Fig. 1). Spatially, what is interesting about the architectural elements of this area is that the gallery is simultaneously an internal and external space. Because the external wall is inside the lobby of the Creative Arts Center and faces a highly trafficked foyer, I felt it was important to transform its appearance. Playing off the title phrase "Oversized

\footnotetext{
${ }^{1}$ David Carlyon, The Education of a Circus Clown: Mentors, Audiences, Mistakes, Palgrave Studies in Theatre and Performance History (New York, NY: Pallgrave Macmillan, 2016), [Page 5].

2 "Wide Load and Oversized Load Banner Requirements By State," US Cargo Control Blog, entry posted 2014, accessed April 23, 2016, http://Blog.uscargocontrol.com.
} 
Load," which typically functions as a warning sign, I wanted to create something obnoxiously eye catching and repetitive. This was done through copies of layered "Oversized Load" text on magenta colored paper. For continuity purposes the same transparencies that were used in silkscreened pieces were also used for the machine copies of the text. In layering the transparencies onto the copier, the intent was to replicate the aesthetics of silkscreen

After assembling a small army of undergraduate students, the exterior wall of the gallery was covered in the brightly hued paper. The bold replicated text became wallpaper that separated this space from the familiar. In the context of location, I wanted to explore the relationship between the Paul Mesaros Gallery and the monotony of our visual landscape. There is an unrelenting routine that seems oddly specific to the Creative Art Center. In transforming an everyday day space that is generally frequented by the same occupants, I aimed to cultivate an air of curiosity and anticipation.

\section{Pyramids: Rubber As Skin}

Focusing on the shape of the pyramid, I constructed five, six-foot tall metal armatures. Thinking in the context of installation based sculpture, my intent was to create something people could walk through. Covering three of the metal forms in rubber, the pyramids ungulate due to altered fans attached to their internal frames. Each form is covered in sewn stretched rubber. Through a basic casting process, I was able to produce the sheets of rubber in thin fabric like squares. Using the Dragon Skin brand silicone rubber allowed for full control over both the color and opacity of each sheet. In terms of color palette, the rubber patches are essentially overly simplified, even stereotypical, hues of "skin" and "flesh". Like Crayola's original "skin color" crayon, the idealized peachy pinks are the dominant color combinations. Though there are some marbling of colors and the addition of a few textured "skin tags," the rubber was mixed with the intent to function as single blocks of color. Colors were generated through mixing five different colors in various combinations. Because each rubber sheet was mixed individually, no two colors are exactly the same.

The use of the rubber celebrates the synthetic. Though this material plays at being skin, I am not concerned with sticking to the confines of the natural world. There is no concern with convincing viewers that this is in the realm of realism. This is very much in the same vein as sex 
toys. In a fun way I am also recontextualizing sex toys into large forms. The title of this piece, All the Sweet Nothings, is really about space and situational intimacy (Fig. 2). I want this installation to simultaneously be object, landscape, and figure. When walking between the large vibrating forms of stitched together rubber, the intent was for viewers to be confronted with feelings of intrusion and anxiety.

The stitching together of skin like rubber also alludes to an element of horror. In the 1950's, serial murderer Ed Gein made a lampshade from the skin of one of his victims ${ }^{3}$. The horror element is also found in the 1991 film Silence of the Lambs, which portrayed a fictional serial killer, Buffalo Bill, who skinned his female victims in order to fashion together a skin suit. ${ }^{4}$ In popular culture, we see characters that are haphazardly sewn together such as Frankenstein and Tim Burton's Sally in Nightmare Before Christmas. The tip of each pyramid is topped with tuffs of purple hair, referencing my own personal self-expression. The triangle shape of the sculptures relates to Maslow's hierarchy of needs, which is also represented as a pyramid. The upper portion of the triangle represents self-actualization, which is attained only when all other needs are met $^{5}$.

\section{Pyramids: Monuments \& Self Concept}

In constructing the large pyramids, I was able to work with large modular forms and create a spatial environment in the gallery. The triangle or pyramid is an object that I view in the context of monumental structure. Historically, these architectural forms were used as memorials to commemorate individuals in power. The Great Pyramid of Khufu is a structure that took over twenty years to build. Interestingly the points of the pyramid are oriented almost perfectly, facing north, south, east and west. ${ }^{6}$ There is something very human about the need to be remembered. However, there is this perpetual disingenuous representation that manifests due to

\footnotetext{
3 Tracy Schwartz, "How Oak Park Actor Became 'Buffalo Bill' in 'Silence of the Lambs.,"' Chicagotribune.com, last modified February 15, 2015, accessed April 23, 2016, http://www.chicagotribune.com/entertainment/ct-silence-of-the-lambs-jame-gumb20160214-story.html

${ }^{4}$ Ben Cosgrove, "Ed Gein: Portrait of America's Original 'Psych Killer'.," Times.com, last modified March 31, 2014, accessed April 23, 2016, http://time.com/3879490/ed-gein-portrait-of-americas- original-psycho-killer.

${ }^{5}$ Kendra Cherry, "The Five Levels of Maslow's Hierarchy of Needs.,"' Verywell.com, last modified April 15, 2016, accessed April 22, 2016, http://www.verywell.com/heirarchy-of-needs-795947\&gt;.

${ }^{6}$ Encyclopedia Britannica, ed., "Pyramids of Giza -Khufu," Britannica.com, last modified 2015, accessed April 23, 2016, http://Brittannica.com/topic/pyramids-of-Giza.
} 
ego. Though these historic forms are tombs, many of these forms began being constructed when their occupants were just reaching their prime. The idea that we spend more time wanting to be remembered than actually living authentically in the moment oddly resonates with modern social media culture.

I see both the hairy and rubber pyramids as ambiguous monuments to the concept of self. In having the structures be uniform, negating any identifying indicators, they become interchangeable. They are simultaneously everyone and no one. Anthropomorphizing a hard, rigid form with hair or rubber and coupling it with my bulbous forms is an interesting relationship to me. The pink pyramids are welded steel with cast rubber stretched and sewn over them. While creating these forms I spent a lot of time looking at Lee Bontecour's sculptures (Fig. 3). Her work seamlessly combines welding with sewn canvas to create these haunting, yet poetic forms. ${ }^{7}$ The concept of using steel as a structure or bones of a sculpture never really connected with me until I started investigating her work. Both fabric and the cast rubber lend themselves to the idea of a "skin".

The triangle has a rich history as both a literal structure and a metaphorical symbol. In Catholicism, the Holy Trinity is represented through a three-sided triangle, symbolic of the Father, Son and Holy Spirit. It is in the center interior of the triangle where "God" manifests. The triangle as a housing vessel for ethereal power is represented throughout many facets of culture. In the realm of the occult, the triangle is used as a summoning symbol. ${ }^{8}$ Like the Holy Trinity, the hollow center of the triangle is viewed as an encapsulating exoskeleton for otherworldly power. It is through the culmination of ritual, faith, and desire that the center is filled with whatever "force" that is requisitioned. Taking the monumental form of the pyramid, I have shrunk them down to be closer in relation to the height of humans. I use the iconography of the triangle as an analogy to the human body, that bodies are flesh vessels that house the "soul".

\section{Pyramids: Fun Fur}

\footnotetext{
${ }^{7}$ Elizabeth Smith and Robert Storr, Lee Bontecour: A Retrospective of Sculpture and Drawing (New York, NY: Henry N. Abrams Inc, 2003), [Page 10].

${ }^{8}$ Catherine Beyer, "Geometric Shapes - Triangles," About.com, last modified 2016, accessed April 22, 2016, http://altreligion.about.com/od/symbols/ig/Geometric-Shapes/Triangles.html.
} 
Due to the rubber pyramids taking so long to construct, it was strongly recommended to me by my committee that I explore different ways of working to better utilize my time. Using the same armatures as that of the rubber pyramids, I created a contrasting "skin". In having two different sets of pyramids, I aimed to have the contrast and proximity facilitate a conversation between the forms and materials. These six-foot tall structures are covered in shaggy fun fur over a welded metal frame. With a turquoise undercoat and pink to purple ombre tufts, the bright hues encapsulate the overall color palette of the exhibition. Additionally, depending on the direction of the nap of the fabric, the tufts pointed different ways creating a subtle sense of difference. From the top of each furry pyramid sprouts a bright turquoise curly mop of hair. Through a series of braids, knots, and ties, the synthetic locks are wrapped around a wire frame. Unlike the vibrating rubber pyramids, the pyramids skinned with fun fur are stagnant, allowing for the hair to provide an implied bouncy quality.

Playing with notions of gender, the pink ribbons that tie the hair provide an over feminization that is intentionally and stereotypically girlie. Coupling hyper-femininity with the monstrously bright fun fur creates a surreal form when stretched across the rigid shape of the pyramid. Though stylistically there are variations in the work, the relationship of materials and how they overlap creates context for the furry pyramids. There is an inherent tactile quality to them, making touch important to the work. Creating forms that are begging to be petted, poked, or gawked at is all part of the spectacle.

The fur lends itself to an association with living creatures. The bright colors give the triangles a fantastical, whimsical quality. The vibrant fur is comparable to the pelts of fictional monsters, like Sully from Pixar's Monsters, Inc, as well as the monsters in Maurice Sendak's book, Where the Wild Things Are. The furry pyramids also draw stylistically from Jim Henson's Fraggle Rock and Dr. Seuss' illustrations of Truffula Trees in the story of the Lorax (Fig. 4). A major commonality throughout the exhibition is juxtaposing heavy, more sinister elements with bright, playful, childlike sensibilities.

\section{Wearable Sculpture}

While siting in on Jason Lee's advanced sculpture class I had the opportunity to be introduced to the work of a lot contemporary artists that I had not been familiar with, particularly 
in regards to the trend in wearable sculpture. Artists such as Rebecca Horn and Tracy Featherstone had never been on my radar before. It was in watching other students tackle an assigned project in that class that I became interested in the relationship between sculpture and the body. That led to my own experimentation with working directly with my own figure.

Cacomorphobia is the fear of fat bodies. ${ }^{9}$ This became the title of the first wearable suit that I constructed. Sewing bullous pink forms on to a jacket, I encapsulated my form in squishy, stuffed sacks. This wearable, sculpture plays with our cultural perception of the obese. Taking the concept of the fat suit, I wanted to push the stereotype to the extreme, physically depicting the grotesque and repugnant way obese people are culturally perceived. This was the starting point for the wearable sculptures that came after.

In constructing the wearable sculptures, I started with forming the headpieces. Using the pyramid as a starting point, I altered the shape using various materials. This included rubber, tissue paper, fun fur, and hair. The top of "I'll Show You a Gorgon" is a welded steel frame covered in fun fur (Fig. 5). Cross-pollinating materials through out the show this two-foot pyramid is also one of the forms included in the All the Sweet Nothings installation. The "formula" for these pieces is a sculptural headpiece coupled with altered garments. In juxtaposing mundane clothing with the fantastical, I aimed to facilitate more empathy from the viewer. I see the ordinary elements as conceptual stepping stones into an imagined space. It also references back to the theme of transformation. The clothes are also important for the different characterizations of the suits. Each of these wearable sculptures is representative of very different personas. Professional Enough is an altered, outdated business dress and hairy pyramid (Fig. 6). The suit embodies the discomfort of being an adult, but never feeling like one, where as Not Everyone Gets to Be Pretty is about how pathetic holding on to unrequited love feels. The suit is literally stripped down to pantaloons, a bra, and the headpiece (Fig.7). My body is dictating the form of the piece. I see the I'll Show you a Gorgon work as really the opposite of that piece, because its body language feels very powerful, like the wearer is ready to take on the world.

\footnotetext{
9 "Cacomorphobia," the free dictionary.com, last modified 2016, accessed April 23, 2016, http://medical-dictionary.the free dictionary.com/cacomorphobia.
} 
As in the installation, the pyramid structure is repeated in all the headpieces. I see the headpieces as simultaneously being masks and conceptual dunce caps. The dunce cap was a systematic form of punishment meant to incite public shame in children who misbehaved. ${ }^{10}$ Like the monster, the dunce cap is a cover used as a dehumanizing method to embody shame. They are physical objects that disallow someone from having an individual identity. This is a physical metaphor for the notion that fatness is not even worthy of a human form. I see these suits as being self-portraits, each exploring different emotive narratives. In a way, I am wearing my own vulnerabilities, putting them on display for the viewer. In Audre Lorde's, Sister Outsider essay, she writes, "Nothing I accept about myself can be used against me to diminish me."11

\section{Character Building: Body Representations and Symbolism}

These suits are not necessarily about acceptance or concepts of beauty, but rather the duality of the human experience. For many people, there is an awkward relationship between the facts that our overweight bodies will eventually kill us one day compared with our day-to-day selfconcept. However, in addressing the perception of the physically grotesque, it impossible not also to recognize the forever changing standards of beauty, as well as the history of body representation. The seventeenth-century, Flemish Baroque painter, Peter Paul Rubens, is best know for the curvaceous women within his counter-reformation compositions. The term "Rubenesque" is a direct reference to Rubens' stylistic choice of women. ${ }^{12}$ These peachy hued ladies were described as having a palatable vastness, embodying the extravagance of the Baroque style, as well as having an alluring sensuality. Though Rubens exhibits diversity in body type, it is solely for the benefit of the "male gaze". As an artist, I am interested in bodily representations that exist without an agenda.

\footnotetext{
${ }^{10}$ Eric Grundhauser, "The Dunce Cap Wasn't Always So Stupid," Atlasobscura.com, last modified September 10, 2015, accessed April 23, 2016, http://www.atlasobscura.com/articles/the-dunce-cap-wasnt- always-so-stupid.

${ }^{11}$ Audre Lorde and Cheryl Clarke, Sister Outsider: Essays and Speeches, Crossing Press Feminist Series (n.p.: Crossing Press, 2007), [Page \#].

12 "Peter Paul Rubins 1577-1640," Nationalgallery.org.uk, last modified 2016, accessed April 23, 2016, https:/www.nationalgallery.org.uk/artists/peter-paul-rubens.
} 
In terms of figurative works, I find John Isaacs' dramatic representations of the obese to be painfully honest. In truth, it is hard to look at some of his forms. One bulbous figure in particular is Isaacs' sculpture I Can't Help the Way I Feel (Fig. 8). The skin is swollen, wrinkled, and chapped in this work, and the fat protrudes from the legs engulfing the arms and head, becoming one solid monstrous mass. Like a giant wad of dirty chewing gum, the body is puckered and repulsive. Isaacs' hyper detailed feet and varicose veined "kankles" literally ground the form. ${ }^{13}$ A lot of my monsters, both illustrated and performance based, are similarly proportioned and missing limbs and heads. I specifically see armless figures as a metaphor for lack of choice. I also tend to discolor the feet of the monsters, stippling ankles in contrasting shades of blue.

Oddly, feet are a point of interest to my illustrative generation of characters. Functioning as both a conceptual and literal foundation, the feet ground the visual imagery of the monsters. I am interested in the impossibility of large body masses being supported by disproportionately small feet. Especially in terms of the two dimensional work, the orientation of the body in relation to the ankles gives the image that sculptural tension of weight distribution. Again, Isaac's I Can't Help the Way I Feel is a good sculptural example of that relationship. This tension is further exaggerated when small high-heeled shoes support the bulbous forms. The monsters wearing heels are drawn so that their feet appear to be crammed into the small space and spilling out. These shoes are often red heels, because the color red is an important symbol in both the wearable suits and monster imagery.

In Hans Christian Andersen's short story, The Red Shoes, shoes function as a cautionary tale against female vanity and the grotesque horror that ultra femininity can "devolve into". In this fable, a pair of red shoes possesses a young girl. The shoes themselves transition from being inanimate objects to becoming a catalyst for brutish change. In the story the girl disobeys her mother by wearing the vulgar shoes to church. The girl is then overtaken by the need to need to dance and does so until her feet become a blistered mess. Even after the feet are forcibly severed, they continue to dance with her bloody remains inside them. ${ }^{14}$

\footnotetext{
13 "Polina Bachlakova, "John Isaacs," helabmagazine.com, last modified June 7, 2015, accessed April 22, 2016, http://thelabmagazine.com/2015/06/07/john-isaacs/\&gt;

${ }^{14}$ Hans Christian Anderson, "The Red Shoes," Hca.gilead.org, last modified 2016, accessed April 22, 2016, http://hca.gilead.org.il/red_shoe.html.
} 
The red shoe carries a subconscious symbol of female sexuality and the feminine ideal, and the red heel is a specific icon of contemporary feminine mythology that functions as an object of power and confidence. A common theme throughout the work is the combination of monstrous forms and characters with this symbol of female confidence. In spite of being monstrous or grotesque, these entities exist unapologetically. Red paint is also used as a visual substitute for this. Like a child smearing on red lipstick, the paint represents how messy the pursuit beauty can be. This is why paint was incorporated primarily on the hands and feet in conjunction with the suits in my work.

\section{Photography: Sculpture Display}

For the exhibition I chose to have these suits displayed primarily in photographs. I chose to work with photography student, Lindsey Cook for her high fashion inspired style. With a commercial background, Cook merges an editorial sensibility with fine art, making her a perfect choice as a collaborator. Being surrounded by a multidisciplinary community is definitely one of the benefits of being part of an academic art environment, and having not only my skills, but also the skills of others at my disposal raised the caliber and diversity of this body of work. Furthermore, I was enabled by others to be catapulted outside my comfort zone. Having the privilege to work with Cook fundamentally changed my notion of what sculpture could be. The series of wearable sculptures we documented together was a surprisingly intimate and liberating experience. The environment of the photo shoot, provided by Cook's professionalism and intuitive nature, facilitated the ability for me to be brave with my work.

As person and an artist, I struggled with the level of vulnerability that happens when you open your body to criticism and display. A major aspect of the suit series is the fact that they are generally displayed through photographs. To get the suits documented I needed to work closely with a photographer. Working with Lindsay, I realized there is a disconnect that exists between my comfort level inhabiting my body as a person compared to inhabiting and using my body for artistic purposes. On a psychological level, as an art object I give my body more permission to exist in the moment than when just being myself. As a woman of size, society projects certain mores on me, but as women we also do that to ourselves. For instance, despite smoldering summer temperatures I would not wear a swimsuit, shorts or short sleeves in public. While there is no chance others will see me as anything less than large no matter what is worn, there is still 
the urge to stay covered and meet social expectations despite the sensibilities of it. However as an art object, I was able to let some of those vulnerabilities go by the wayside.

\section{Photography: Influences}

I find the cross pollination of sculpture, high fashion and performance based art to be such fruitful ground. In the context of art history, it is fairly new territory. I find both the leather creations of Erica Gray and the sculptural garments of Amsterdam fashion house Viktor \& Rolf to be so formally beautiful. However, it was really the discovery of Nick Cave's work that solidified the notion that object making and performance could coexist with in the same piece.

Nick Cave creates absolutely stunning sound suits that are both visually dynamic and functional wearable sculpture pieces (Fig.10). In 2010 his sound suits were featured in an eightpage spread in the September issue of Vogue. Shot by fashion photographer, Raymond Meier, Cave's suits take center stage, each shot against a stark white background. The almost harshly clean background allows for every detail of the suits to pop, with the suits taking up the majority of the composition. ${ }^{15}$ Stylistically, how Cave poses his suits for documentation directly informed how I modeled mine. Even though his suits are packed with dynamic and intricate details, when there is a person modeling it, that presence is not lost. Suits are often twisting, bending or squatting, the body moving in a way that emphasizes the composition of the suit and body as one sculptural form.

In terms of photography, Cindy Sherman's conceptual self-portraits are a huge influence. In every photograph she is essentially recreating herself with makeup, costumes, and practical effects (Fig. 11). In some she is representing female clichés of 20th-century pop culture, while others are purely emotive. ${ }^{16}$ Her willingness to allow her photos to be whatever they need to be, whether it's beautiful, disturbing, or grotesque, feels intimately honest. Her work encompasses the performative act of gender. Sherman examines and distorts cultural notions of femininity and the social construction of gender identity. Embodying stereotypes, she takes her

\footnotetext{
${ }^{15}$ Andrew Bolton, Elvira Dyangani Ose, and Nato Thompson, Nick Cave: Epitome (New York, NY: PRESTEL, 2014), [Page $12,17,21]$

16 "Cindy Sherman," Moma.org, last modified 2012, accessed April 22, 2016, http:/Moma.org/interactives/exhibitions/2012/cindysherman/.
} 
representations to the extreme. In the context of my own wearable sculptures, I am intentionally dramatic in the rendering of forms to point out everyday notions and criticisms. "We make our own monsters, then fear them for what they show us about ourselves."

\section{Performance: Models \& Theater}

I found a profound significance in using my body as a sculptural element. Performance art is really about owning your own visibility. During the exhibition reception, in order to have more than one suit activated, I sought out other women to wear them. The process of staging an event and having multiple people modeling my wearable sculptures was a very interesting learning experience. First off, I made my suits very much from the sculptural sensibility, not from that of a practical costume. Furthermore, the headpieces and clothes were built for and tailored to my body specifically. Though the models are wearing the suits, they were really models, pretending to be me, modeling the sculptures.

An example of the role of performance art stand-ins occurred in Marina Abramovic's 2010 retrospective, detailing her prolific career as a performance art pioneer. Abramovic's exhibition was a mixture of video works, installations, photographs, solo performances, and collaborative performances made with her partner of that time, Ulay. In The Artist is Present, a documentary about this exhibition, it actually shows Abramovic training her performers at a strange, conceptual boot camp for the arts. ${ }^{18}$ This is a good example of how quality, endurance, and performance length can be extended when you are not paying models with pizza.

As an artist interested in "world building", I draw a lot from the realm of Cirque du Soleil. This contemporary international circus explores whimsical visual language and dream like narratives. When looking at these shows in the context of costume design, they are incomparable. This Canadian entertainment company is the largest theatrical producer in the world. The song I chose to play in the gallery during the reception, in tandem with the live models, was "Marelle." Marelle is a French game similar to American hopscotch. ${ }^{19}$ The song,

\footnotetext{
17 "Mike Carey Quotes," Goodreads.com, last modified 2016, accessed April 23, 2016, https://www.goodreads.com/author/quotes/ 9018.Mike_Carey.

18 "Preparing For Performance Art With Marina Abramovic," Gnomemag.com, accessed April 23, 2016, http://gnomemag.com/preparing-for-performance-art-with-marina-abramovic/.

19 "Cirque du Soleil History," Cirquedusoleil.com, last modified 2015, accessed April
} 
which is primarily sung by a young female vocalist, is both playful and haunting. Like many Cirque du Soleil songs, the language of the lyrics is completely made up, letting the music and emotions of the singer convey the meaning of the piece. In regards to "Marelle," there is an element of repetition in the music that I felt resonated with the feeling of my work, for instance, the constant visual repeating of the title phrase "Oversized Load". The background instruments in this song have these quick fluctuating ups and downs similar to a carousel tune. ${ }^{20}$ Overall, I felt the music of "Marelle" lent itself to the theatrical circus atmosphere of the exhibition while still being subtle.

This song is part of the Cirque du Soleil show Quidam. Benoit Jutras, a prominent composer known primarily for his works in contemporary circuses throughout the international community, composed the music for this show. Quidam is the Latin word for an unspecified or inconsequential person. This is the ninth stage show produced by Cirque du Soleil. The narrative of the show is structured around the imaginings of a bored girl named Zoe. Due to feelings of isolation and alienation by the people around her, Zoe escapes into her mind. It is there that the fictional world of Quidam comes to life. ${ }^{21}$ Conceptually I relate to the concept of "world building". I approached the work, the exhibition, and even the reception in a very holistic sense. Though sculptures can function as individual pieces, I see each element of the exhibition as creative scaffolding that supports the overarching universe that my work inhabits . Akin to Alice falling down the rabbit hole in author, Charles Lutwidge Dodgson's 1865 novel, I wanted each viewer to feel transcended.

\section{Imagery: The Monster}

The imagery of the large monster cutouts evolved over the course my time at WVU. During my first semester I spent a lot of time making playful paper maquettes that I saw as a collective visual image bank. These were primarily monster-based illustrations. Though I didn't necessarily view these works as finished pieces, I was encouraged by my faculty to pursue that

\footnotetext{
2016, https://www.cirquedusoleil.com/en/press/kits/corporate/cirque-du-soleil/history.aspx.,

20 "Quidam Cirque du Soleil," Topdocumentaryfilms.com, last modified 2016, accessed April 22, 2016, http://topdocumentaryfilms.com/ cirque- du-soleil-quidam/.

21 "Cirque du Soleil History," Cirquedusoleil.com, last modified 2015, accessed April 222016, https://www.cirquedusoleil.com/en/press/kits/corporate/cirque-du-soleil/history.aspx
} 
vein of imagery and mixed media process. While taking painting, I decided to scale four of the monster maquettes up into paintings. These four monsters were the "The Cunt, Muffin Top, Sassy Gassy, and Bushy Cyclops" (Fig.11). These images then became medium sized, mixed media paintings. Like the maquettes, these illustrations were a mixture of paint, pen, and heavy marker stippling. Still not feeling satisfied with the finished product of the monsters, I decided to digitize the paintings and have them printed as stickers. Sticker Mule is both an economical and timely printing business that facilitates everything through the Internet. Sending work out to be manufactured by someone else was a huge and liberating realization in my art practice. Stickers are a playful and approachable way of dispersing images out into the world. Stylistically, sticker art is almost the visual love child between street and comic book styled art. Travis Millard of Fudge Factory Comics is an artist who I follow religiously on social media. Millard makes deliciously weird illustrations, prints, zines and stickers. There is an accessibility to these art forms that is appealing and also very community based. Sticker art can travel and be collected or traded like baseball cards.

In looking at end game for the exhibition, I still felt very much invested in these particular four monsters. However, since the size of objects are often dwarfed in a gallery, it was now important to scale the images up. Also, since the show title encompassed themes of largeness, I wanted these forms to take up and truly inhabit the space. However, this turned out to be a process that included passing the project off to a different artist with the skill sets necessary to reach the desired goal. For example, in order to print such large images, I had to send in a file sized with the appropriate amount of pixels. Using a grid like system a photography student took multiple photos of each of the original monster paintings. The student then "stitched" each of the images together to create a large format photo, large enough to be printed five feet in length. Those files were then passed to another individual, who edited them in Photoshop before they were sent out to Morgantown Blueprint to be manufactured.

Once all the monsters were printed as large foam cut out outs, there was a final person who constructed the display brackets. The monsters were hung against the purple wall with the brackets enabling them to float in space in front of the wall. Cast shadows and the curve of the monster prints give these two-dimensional works a more sculptural presence. I think this project really embodies the notion that art can have many lives. It is not cheating if something gets 
configured multiple times. Furthermore, making art takes a village and bringing other people's skill sets to the table is essential in reaching large-scale goals.

\section{Two-Dimensional: Influences}

Stylistically, I draw inspiration from 90's popular culture along with the bright colors and clashing patterns of that era. The majority of the non-art influences I have relate directly to my childhood, which also speaks to the nostalgic sensibility of the work. Especially in regards to the two dimensional pieces, iconic Nickelodeon cartoons such as Ren \& Stimpy, Rocko's Modern Life and AHH Real Monsters, inform my illustrative style. Specifically in AHH Real Monsters, there is a male called "The Grumble", who wears red high heels on all four of his feet (Fig.12). This particular character has made me consider how coupling icons culturally associated with gender; a fantastical, grotesque character can create powerful imagery.

Another major influence that relates directly to my child hood is the children's books Scary Stories to Tell in the Dark. Stephen Gammell originally illustrated these short stories, written by author Alvin Schwartz in 1981. These hauntingly grotesque illustrations were inspired by Francisco Goya etchings such as To Rise and to Fall, 1799. Gammell's images are composed of scratchy thin lines and gray watercolor-like background. ${ }^{22}$ The story and illustration of "THE BIG TOE" became a fundamental starting point in my evolution as an artist and what I find visually interesting. The toe also embodies the polarization of the perception of flesh. It's something that can be both fetishized and repulsive. Artistically, I am very much interested in the intersecting space of those notions.

In terms of art history and the depictions of monsters, I feel the perception of the Greek myth of Polyphemus is significant. Odilon Redon's painting The Cyclops, 1898, is an emotional reconceptualization of an ancient character(Fig.13). Classical descriptions of Polyphemus describe him as a depraved man eating monster. ${ }^{23}$ In Homer's "Odyssey," this Cyclops is certainly portrayed as a villain. Historically Polyphemus has been the gross embodiment of lustful vengeance. According to myth he harbored an insatiable yet unrequited love for the sea

\footnotetext{
22 “Alvin Schwartz, Scary Stories To Tell In the Dark, illus. Stephen Gammell (n.p.: Scholastic, 1981)

23 "Polyphemus," Brittanica.com, last modified 2016, accessed April 23, 2016, http://www.britannica.com/topic/PolyphemusGreek-mythology.
} 
nymph Galateia. ${ }^{24}$ However over time depictions of this character softened, for example as in Gustave Moreau's painting, Polyphemus spies on the sleeping Galatea, 1880. In Redon's painting however, all the wildness and malice has been tamed out of Polyphemus. This Cyclops feels like a friendly fixture in the pastel landscape as he gently looks down at the sleeping Galateia. All these variations of Polyphemus speak to the power of visual storytelling and how the intent of a character is often discerned by their physical portrayal.

\section{Printmaking:}

Taking printmaking shifted my attitude towards multidisciplinary practices, helping me see my two-dimensional work as an equally valid part of my art making practice. During this last year specifically, I genuinely fell in love with silkscreen processes. Contemporary artists such as Swoon, Nicola López, Ryan McGinness, and others blur the boundaries between traditional printmaking techniques and sculptural installation. I never want to be constrained by a predetermined medium. Interacting with art in a completely new way introduced me to a lot of illustrators, zine makers, and visual styles. Some of the contemporary printmakers I have been looking at include Gregory Jacobsen and Joan Cornell. Both artists really marry disconcerting imagery with humorous sensibilities. I am especially drawn to Jacobsen's bright colors, strong graphic lines, and raunchy imagery. Visiting artist Sage Perrott, also known as HEYPEEP, is also a printmaker whose work resonated with me.

Artistically, I see my monsters as an investigation of screen-printing processes, while also taking my love of drawing and character generation into the third dimension. My installation Couch Potatoes is a collective pile of homemade pillows surrounding a blow up couch (Fig.14). The pile consists of 137 silk-screened monster plushies and various pillows. Mixing in with the monster imagery, there are fun fur triangle pillows, along with blobby, stuffed forms with "Oversized Load" printed fabric. There are also two sets of pillows that spell out the word "fat". These are all made with materials that recur throughout the exhibition. The fabric is a mixture of vintage textiles and bold contemporary prints. Although I was not concerned with having prints match, the primary color palette is composed of pinks and oranges with splashes of blue.

\footnotetext{
24 "Persephone," Greekmythology.com, last modified 2016, accessed April 23, 2016, http://www.greekmythology.com/Other_Gods/Persephone/persephone.html.
} 
The monster prints are displayed in a sculptural and seemingly casual manner. I see the "art pile" as a classical visual theme in installation art that I wanted to pay homage to. Michelangelo Pistoletto's, Venus of the Rags, 1967, was the first contemporary sculpture I ever saw in person at The Hirshhorn Museum, in Washington D.C. Viewing the piece as child, I remember thinking that it looked more like my sister's bedroom than actual art. However, the concept of "the pile" embodies ideas of accumulation, mass, commodification, and how we assign value to objects. Accumulation is also a way of creating visually large work that is easily reconfigured and modular.

In this piece, I am interested in the idea of precious mass. Typically, piles are gratuitous, things that are collected without thought. However I wanted to explore what would happen if everything in a massive pile were handmade and meticulously embroidered. Conceptually, the title Couch Potatoes is taken from a notion that obese people are lazy. Subverting that notion of the couch potato, I am reversing the physical point of connection the "potato(s)" has with the couch. Thus instead of a person, all the pillows and monsters encapsulate being engulfed by a couch. Furthermore, many of the monsters have toes so "pota-toes" is a cheesy, yet appropriate pun.

The relationship between mass and furniture is another common theme in contemporary sculpture. Yayoi Kusama altered multiple chairs, engulfing them in sewn potato-like forms, such as her piece Accumulation, 1963 (Fig.15). ${ }^{25}$ Artist Jessica Jackson's entire body of work centers around the positioning and weight distribution of ceramic forms on domestic structures (Fig.16). ${ }^{26}$ I chose to display the handmade objects with a blow up couch because I wanted to ground the whimsical imagery with a physical object. In terms of this particular couch, I was interested in the relationship between the Chesterfield style sofa and the absurdity of it being inflatable furniture. Chesterfield has a long rich history of being associated with class, wealth and status. This distinctive furniture style was originally designed as a gentleman's couch, commissioned by Lord Phillip Stanhope, the 4th Earl of Chesterfield in 1694. The distinctive deep inset buttons and taut leather has become a signature fixture associated with traditional

\footnotetext{
${ }^{25}$ Laura Hoptman, "Yayoi Kusama's Return to Moma," Moma.org, last modified October 9, 2012, accessed April 23 , 2016, http://moma.org/explore/inside_out/2012/10/09/yayoi-kusamas-return-to-moma/.

26 "Jessica Jackson Hutchins," Saatchigallery.com, last modified 2016, accessed April 23,

2016, http://www.saatchigallery.com/artists/jackson_hutchins.htm?section_name=paper.
} 
male dominated occupations and spaces. ${ }^{27}$ Again referencing 90's popular culture, inflatable furniture was what I thought being an adult looked like as a kid. Taking this symbol of masculine professions, I am engulfing it in feminine chaos.

\section{Reception: Myth \& Gluttony}

Using the refreshment table as an intentional element of the exhibition, I aimed to have it be an installation in and of itself. Serving an overabundance of cookies and candy, complete with the obscenely sweet smell of a chocolate fountain is stereotypical embodiment of gluttony. Long has a banquette table filled with indescribable decadence been used a narrative device to test a protagonist's will against temptation. There is a long history that cautions travelers of the repercussions of eating food that is not their own. This is a thematic plot device commonly referenced in both mythology and folklore.

One of the most well known examples of this superstition is seen in Greek mythology. Anytime a living traveler journeyed to the underworld they are warned never to eat anything. In one story Hades, god of the underworld, abducted Persephone, the daughter of Zeus and Demeter, to be his wife. The vegetation goddess had no desire to remain in the underworld but because she ate a handful of pomegranate seeds she had to forever remain in the underworld part of each year. $^{28}$

Food related myths also exist in the European folklore of the land of the Fae. A contemporary representation of this mythology is in the 2006 film Pan's Labyrinth directed by Guillermo del Toro. The film takes place in falangist Spain of 1944, five years after the Spanish Civil War. ${ }^{29}$ The intensely political and militaristic characters juxtapose with rich dark fantasy. The main character, a young girl named Ofelia is led into a labyrinth where she is given three tasks by a faun. The second of the three tasks was to reclaim an ornate dagger from a childeating monster. The "pale man" is a grotesque monster with loose, wrinkled flesh. Decorative frescoes line his lair, illustrating the fates of children who had previously wandered in. The

\footnotetext{
27 "Chesterfields of England," Chesterfields.co.uk, last modified 2015, accessed April 22, 2016, http://www.chesterfields.co.uk.

${ }^{28}$ C. Scott Littleton, Mythology: The Illustrated Anthology of World Myth and Storytelling (London, UK: Duncan Baird, 2002), [Page 31].

29 “Pan's Labyrinth, directed by Guillermo Del Toro, 2007.
} 
monster remains inanimate, sitting silently in front of a large feast. Specifically instructed not eat anything from the table, Ofelia gives into temptation. One bite of food awakens the Pale Man, his movements are rigid as he comes to life, and inserting eyeballs into terrifying hands, the chase begins. Though these foods are used as cautionary tales, they are also essential in helping shape the world they inhabit and the intent of the characters in these narratives. Like the witch in the German fable Hansel and Gretel, I used confectionary delight to draw people into my world. I am interested in the relationship between sensory pleasures and play merging with darker elements of the grotesque.

\section{Reception: Monster Masks}

Another aspect of the show that only happened during the exhibition reception was the handing out of monster masks. Like the plush pillows I used the process of silk-screen. These accumulated to a total of 130 prints. There were three types of monsters and each print addition is three layers. These are used to solidify the concept of the mythology of transition and to evoke a sense of play. The masks are an actual physical change when viewers put them on while entering the gallery space. Using masks I hoped to engage the viewers more with the live models. I see the mask as equalizing the viewer's gaze with that of the works. The masks allow for a visual merging of art and characters. People go into a gallery with the expectation of actively looking at something. It was important for me that viewers did not approach the work as an outsider, but as part of the collective "them" which then becomes an "us". In incorporating the viewer I am blurring those distinctions. More then anything, I wanted this collective experience to evoke empathy from the viewers, illustrating that our relationship with the other is situational and that at any given moment the focus can shift to us. On the back of every mask I placed this poem by David Jones. ${ }^{30}$

"You cannot create a monster and then condemn it.

Hate its ugly features, its terrible gait.

When I look into the mirror I do not see myself, but all of you who made me".

\footnotetext{
${ }^{30}$ David Jones, Could You Ever Live Without? (Colorado Springs, Co: Create Space Independent Publishing Platform, 2013)
} 


\section{Conclusion}

Over all I see the work of this exhibition as an intersection between personal narrative and social commentary. As humans we are constantly grappling with insecurities and difference. This work explores those differences on both personal and social levels. Through immersive installation and character building I am creating my own visual mythology. As artists we are always asked "who is our audience, who are we making work for." My art is for anyone who knows what it feels like to eat lunch alone in a bathroom stall. This is for people who have never learned how to rest easy in their own skin. So often conversations about bodies are polarized into either over-glorification or self-deprecation. However as an artist, I just want to be unapologetically honest about the good, the bad and the ugly. 


\section{IMAGES}

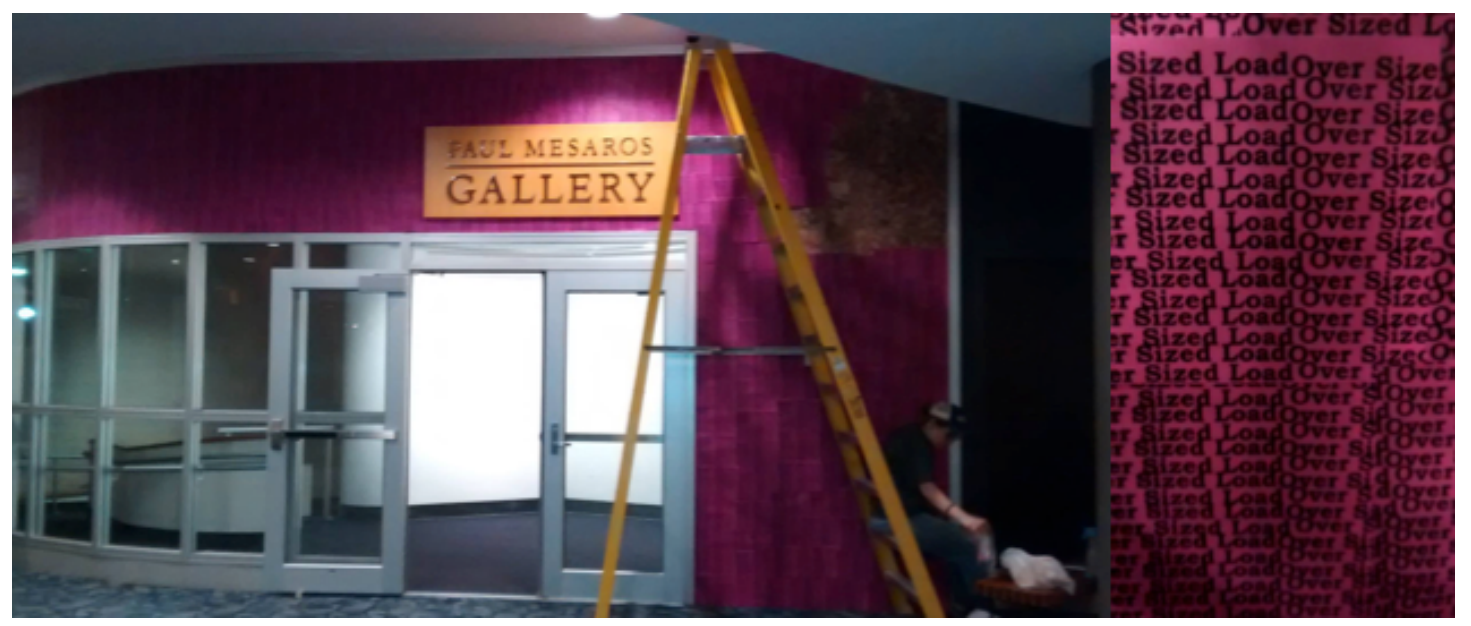

Fig.1 External wall of the Paul Mesaros Gallery Installation shot.

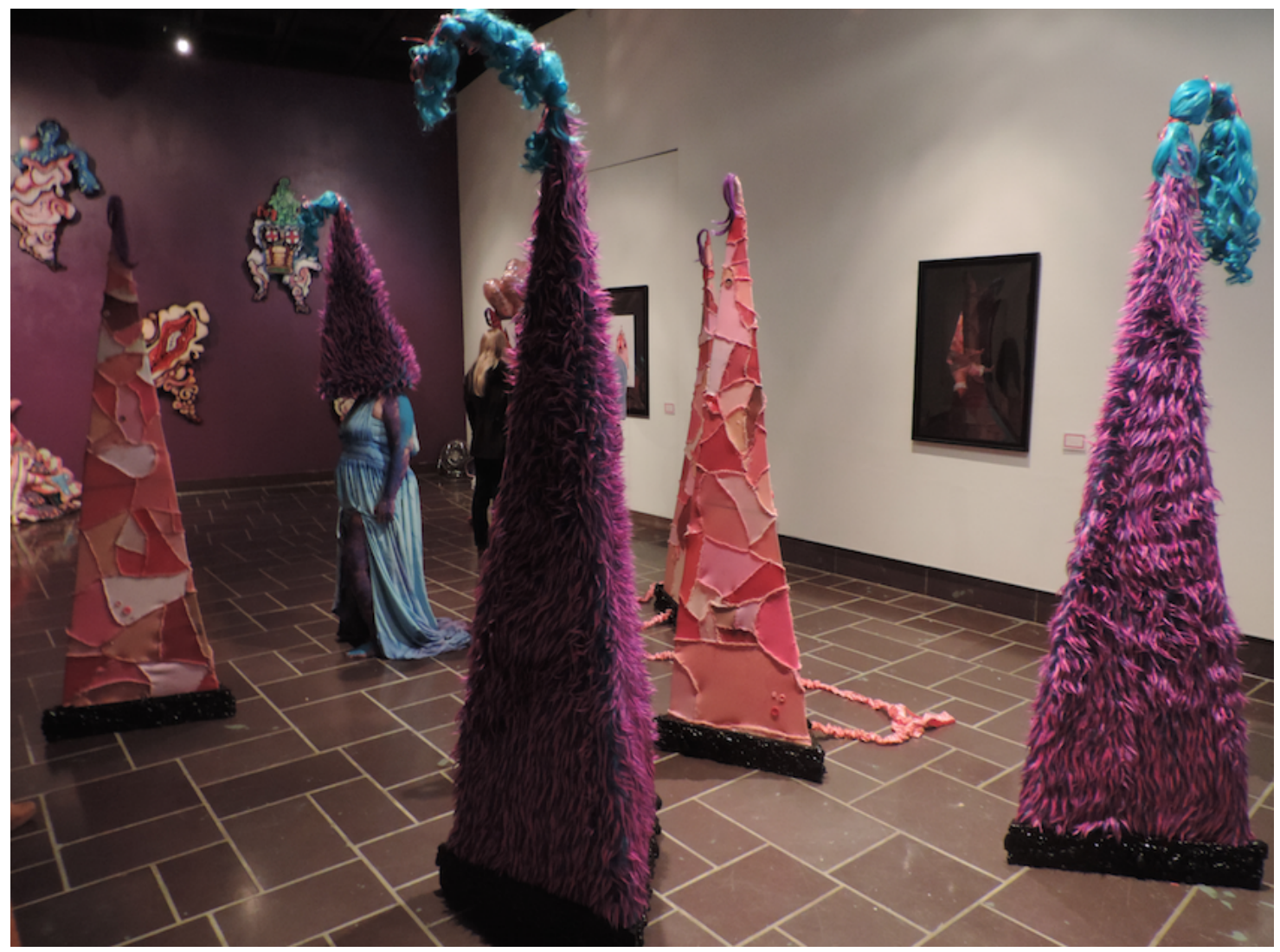

Fig.2 "All The Sweet Nothings", Installation shot of from Oversized Loa 


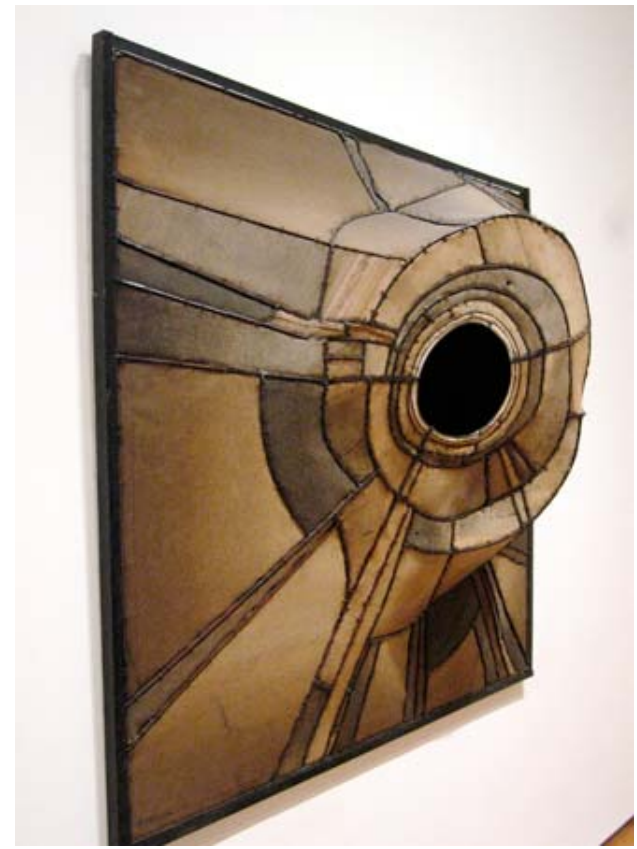

Fig.3 Lee Bontecou, Untitled, welded steel, canvas, black fabric and wire, 1959

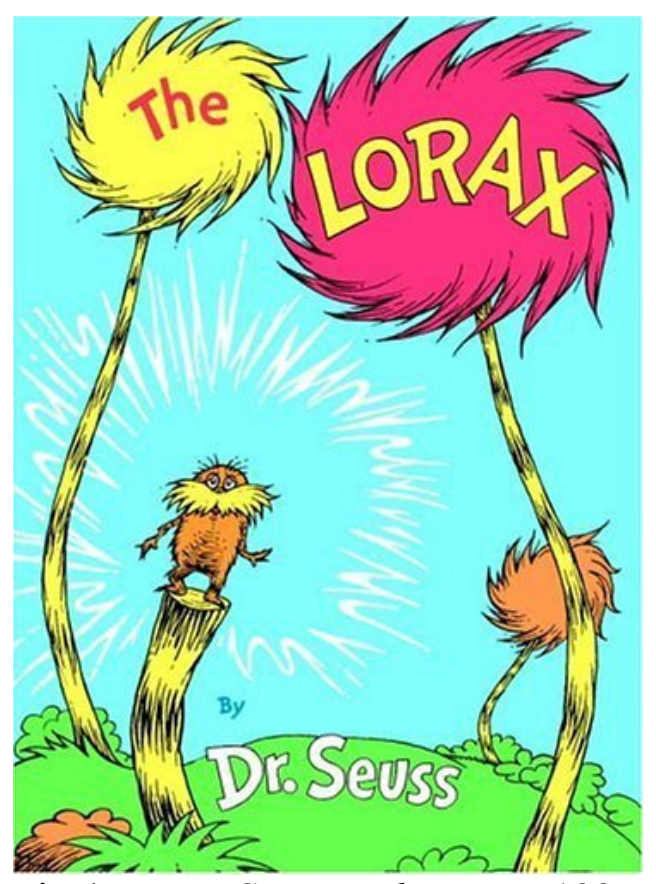

Fig.4 Doctor Seusss, The Lorax 1997 


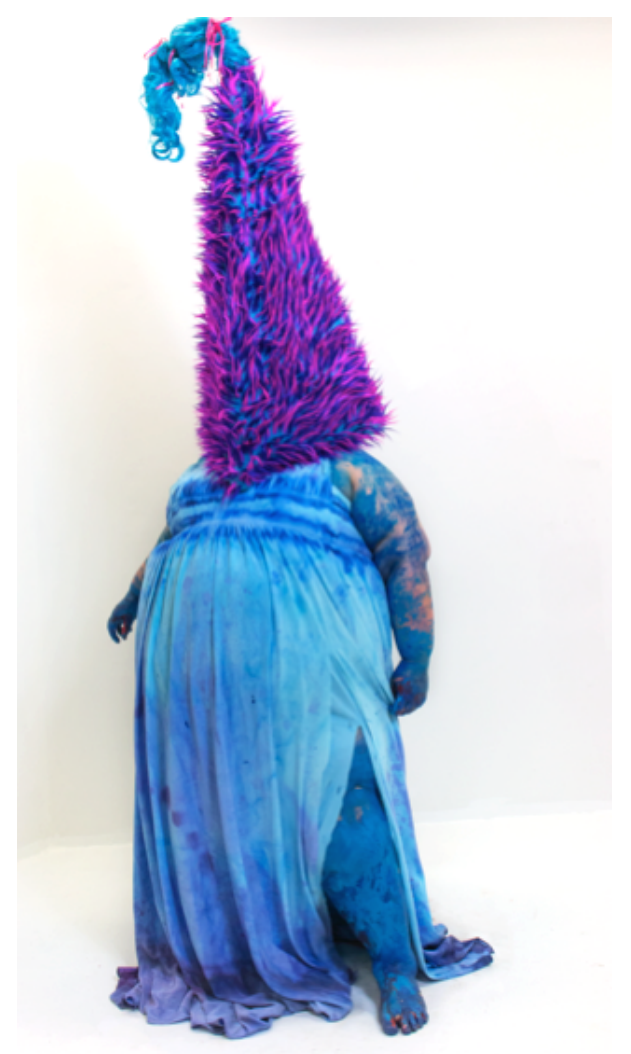

Fig. 5 I'll Show you A Gorgon, wearable sculpture, 2016

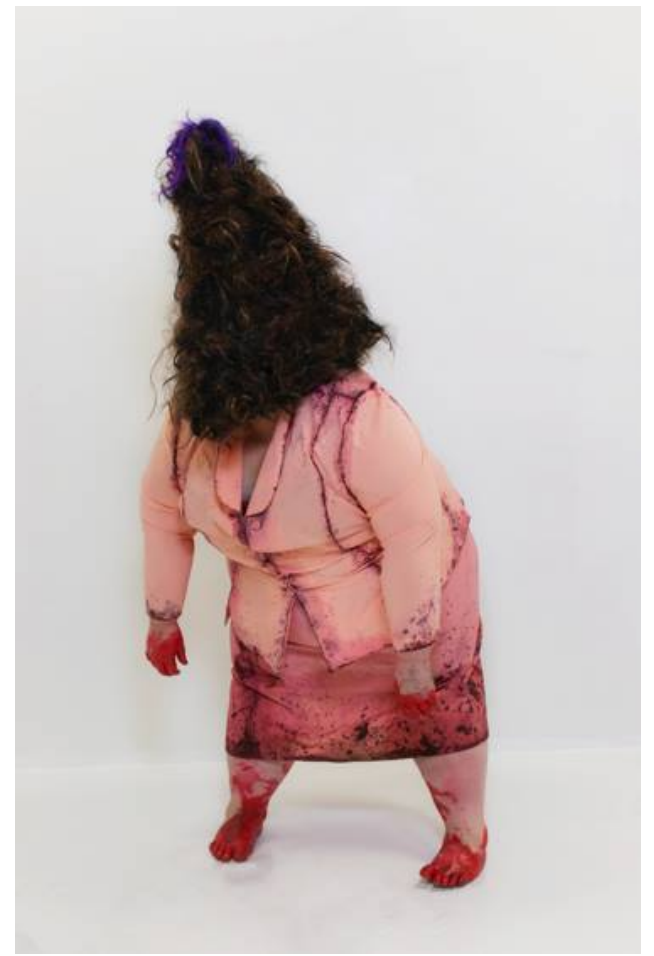

Fig. 6 Professional Enough, wearable sculpture, 2015 


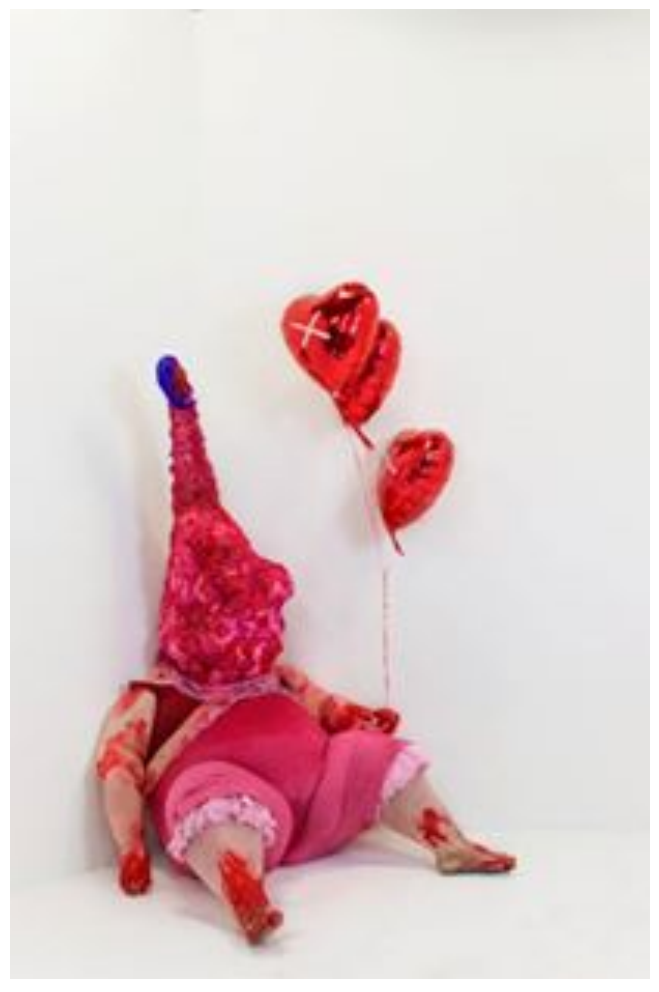

Fig. 7 Not Everyone Gets To Be Pretty, wearable sculpture, 2016 


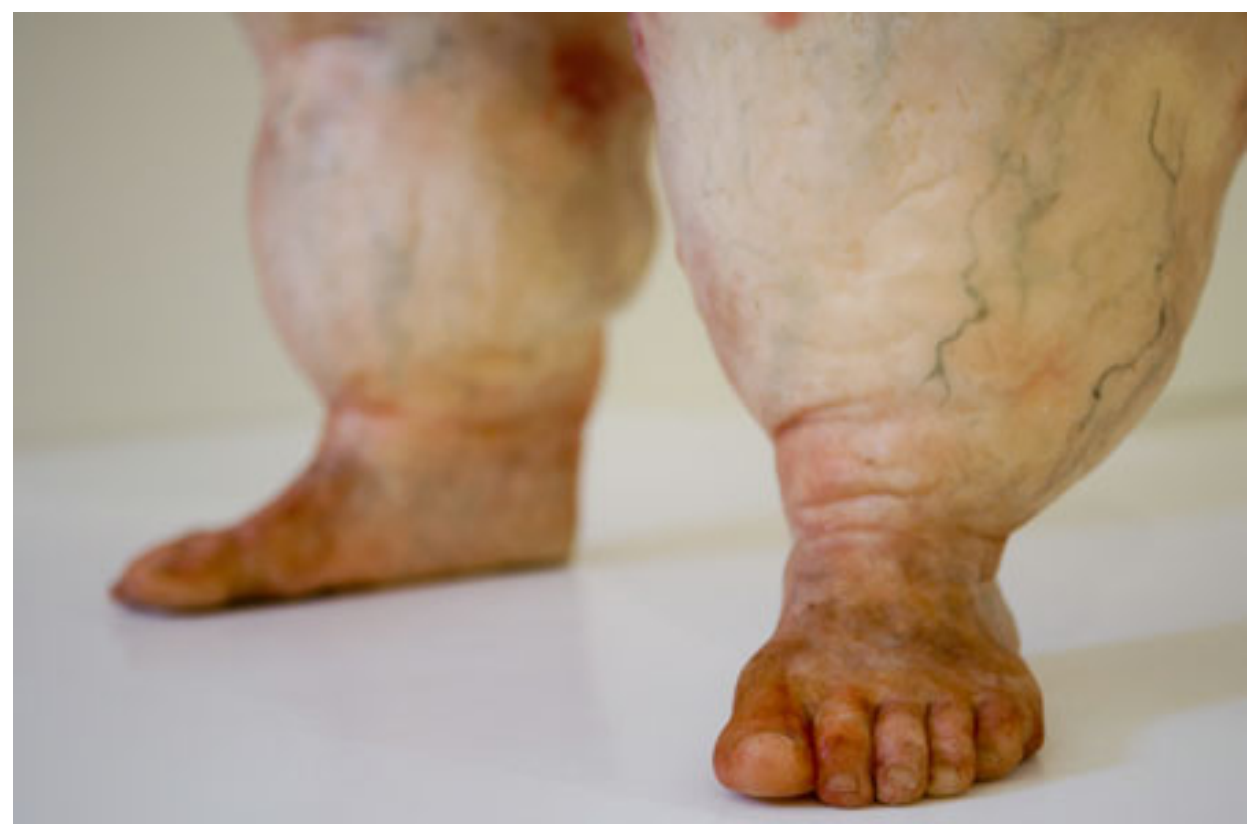

Fig. 8 John Isaacs, I Can't Help How I Feel, wax, resin, polystyrene, steel, 2003 


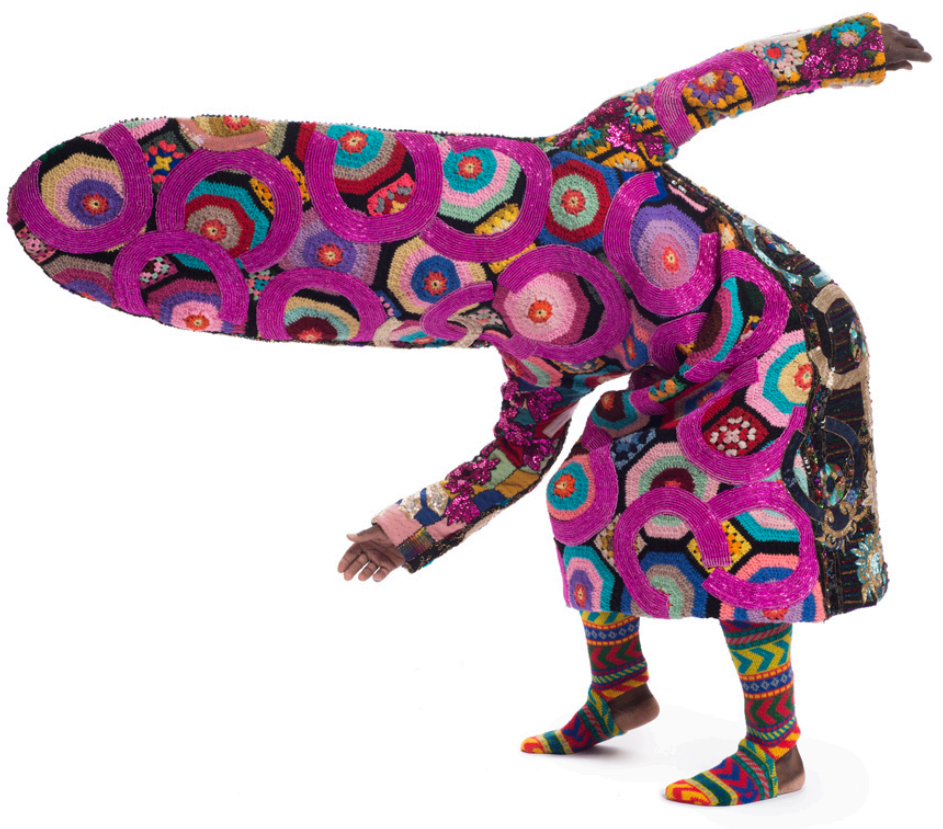

Fig. 9 Nick Cave, Sound Suit, crochet blanket and sequins, 2013
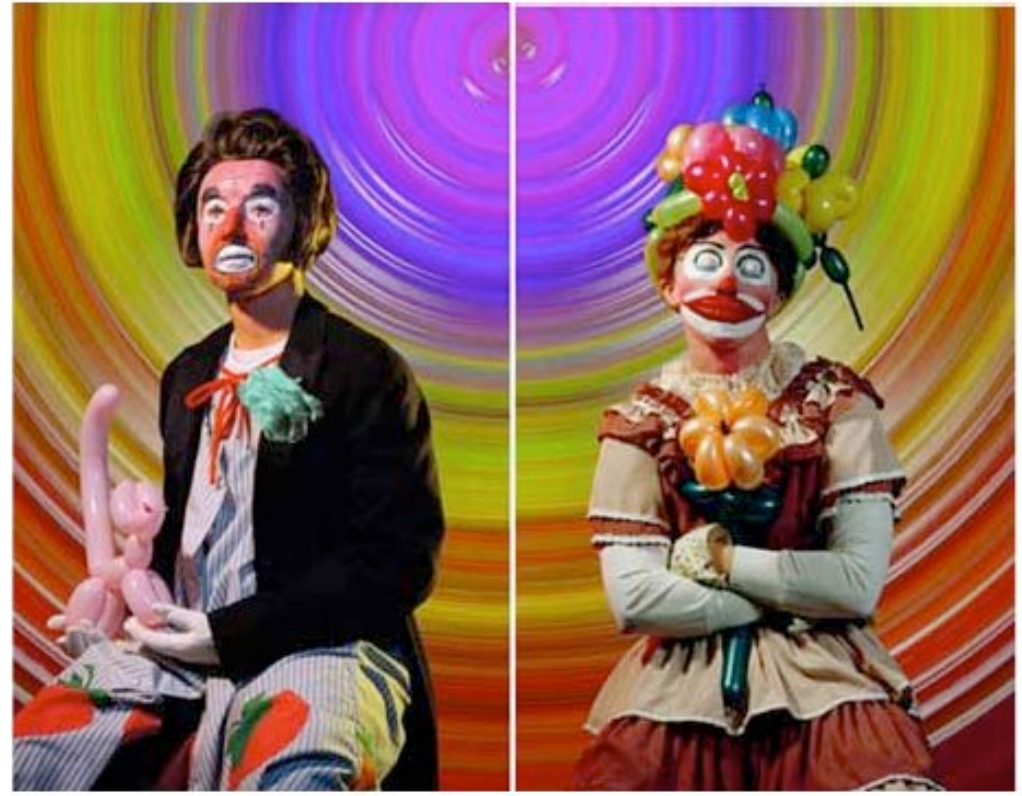

Fig.10 Cindy Sherman, Untitled \#420, chromogenic color print, 2004 

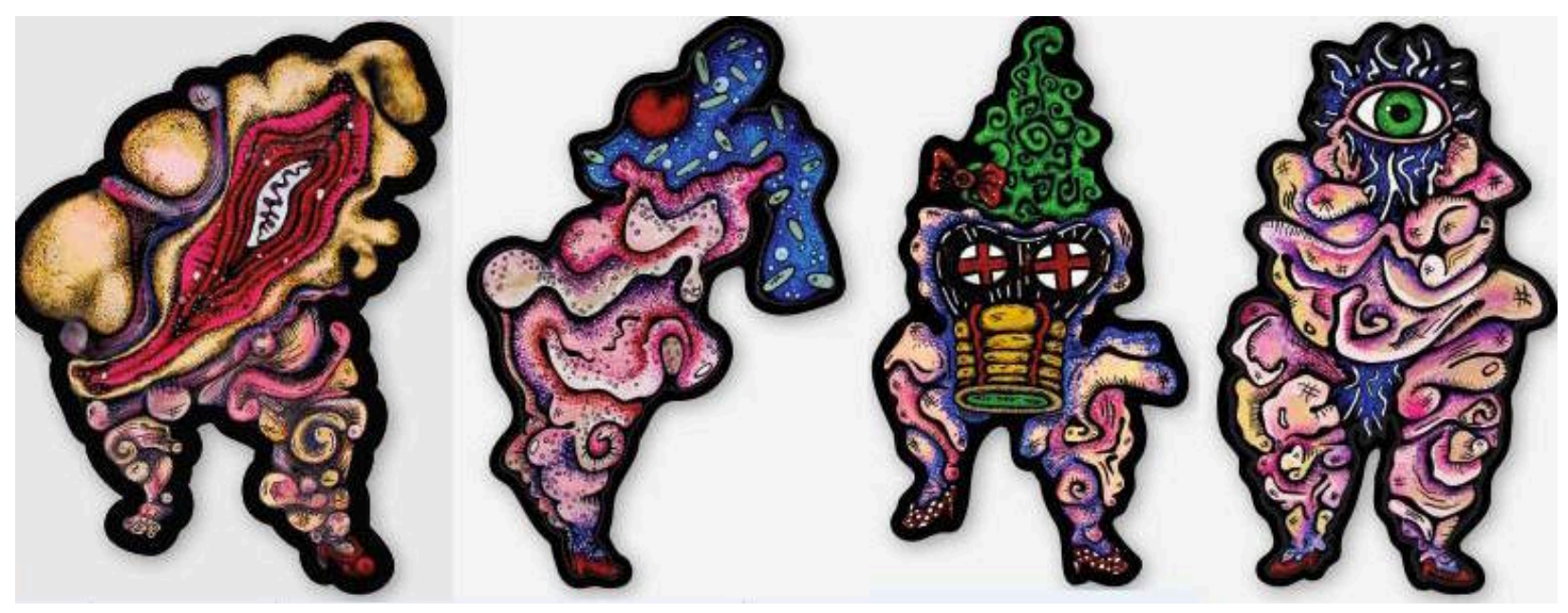

Fig. 11 Monster Stickers

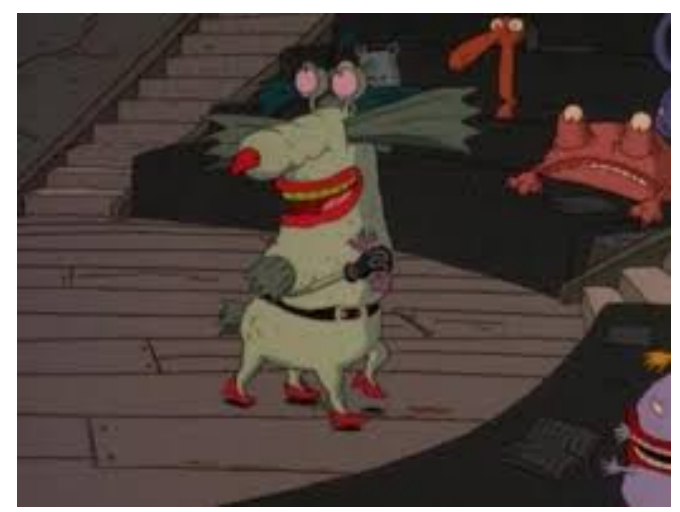

Fig. 12 Nickelodeon, AHH REAL MONSTERS, 1994 


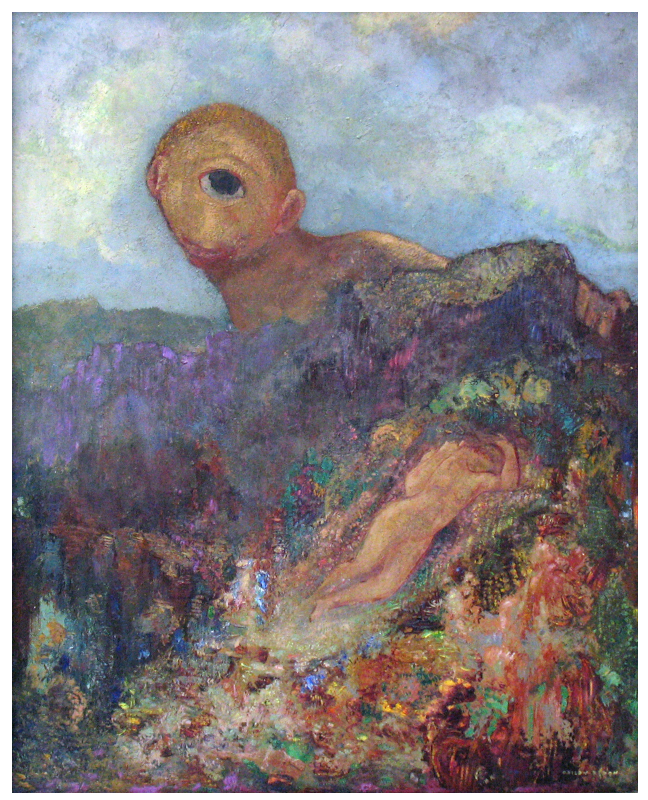

Fig. 13 Odilon Redon, The Cyclops, 1898

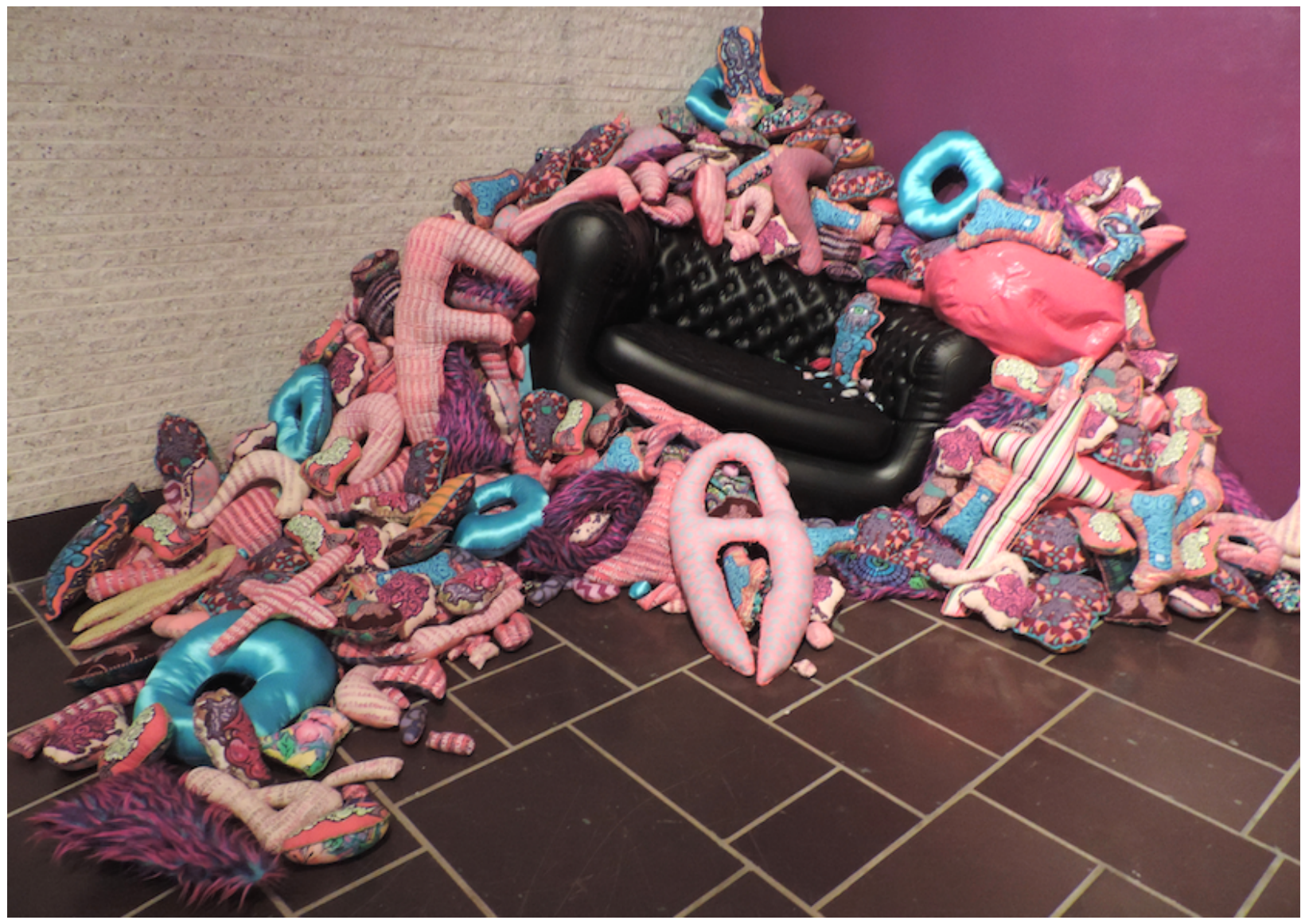

“Couch Potatoes”, silk-screen, fabric, couch, 2015 


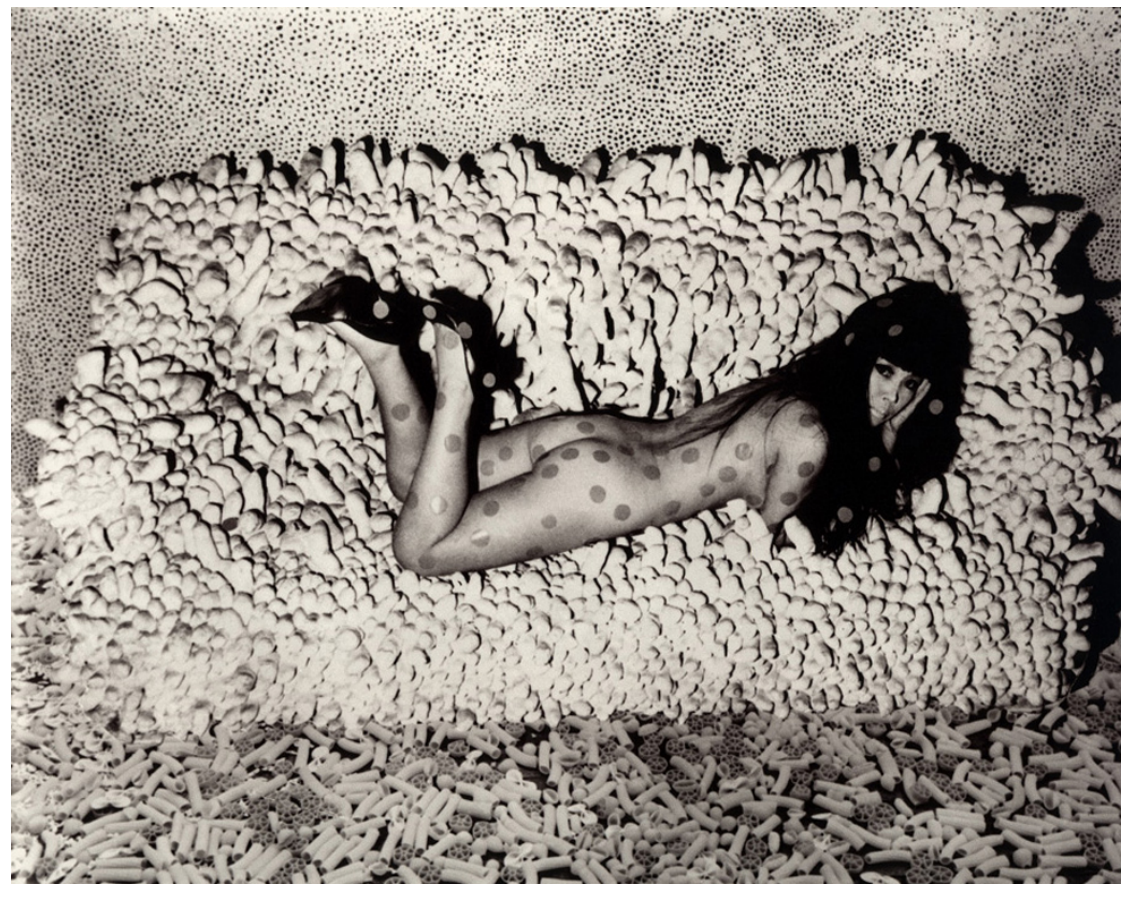

Fig.15 Yayoi Kusama, Accumulation, 1963

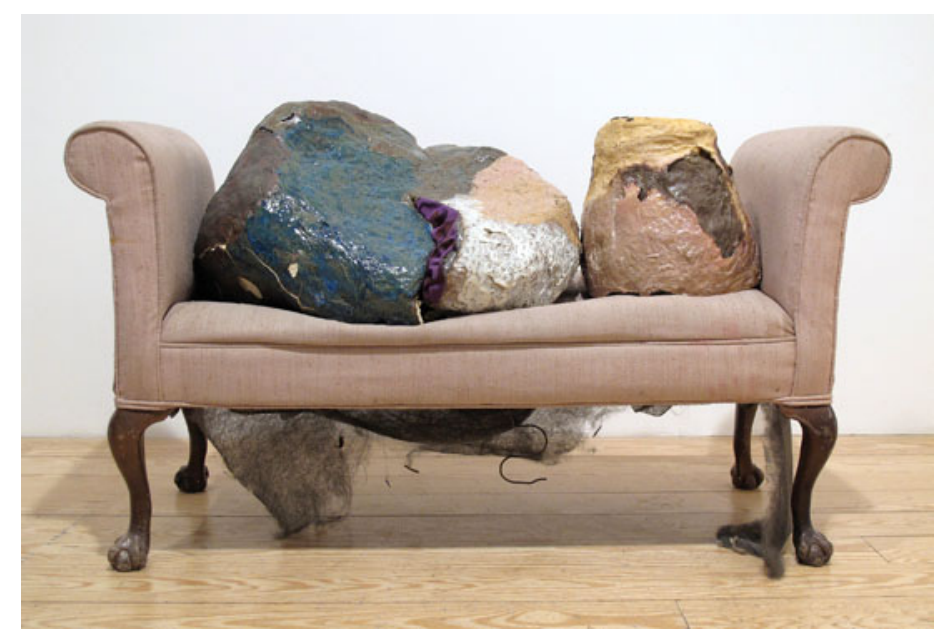

Fig.16 Jessica Jackson, Settee, ceramic, fabric, 2010 


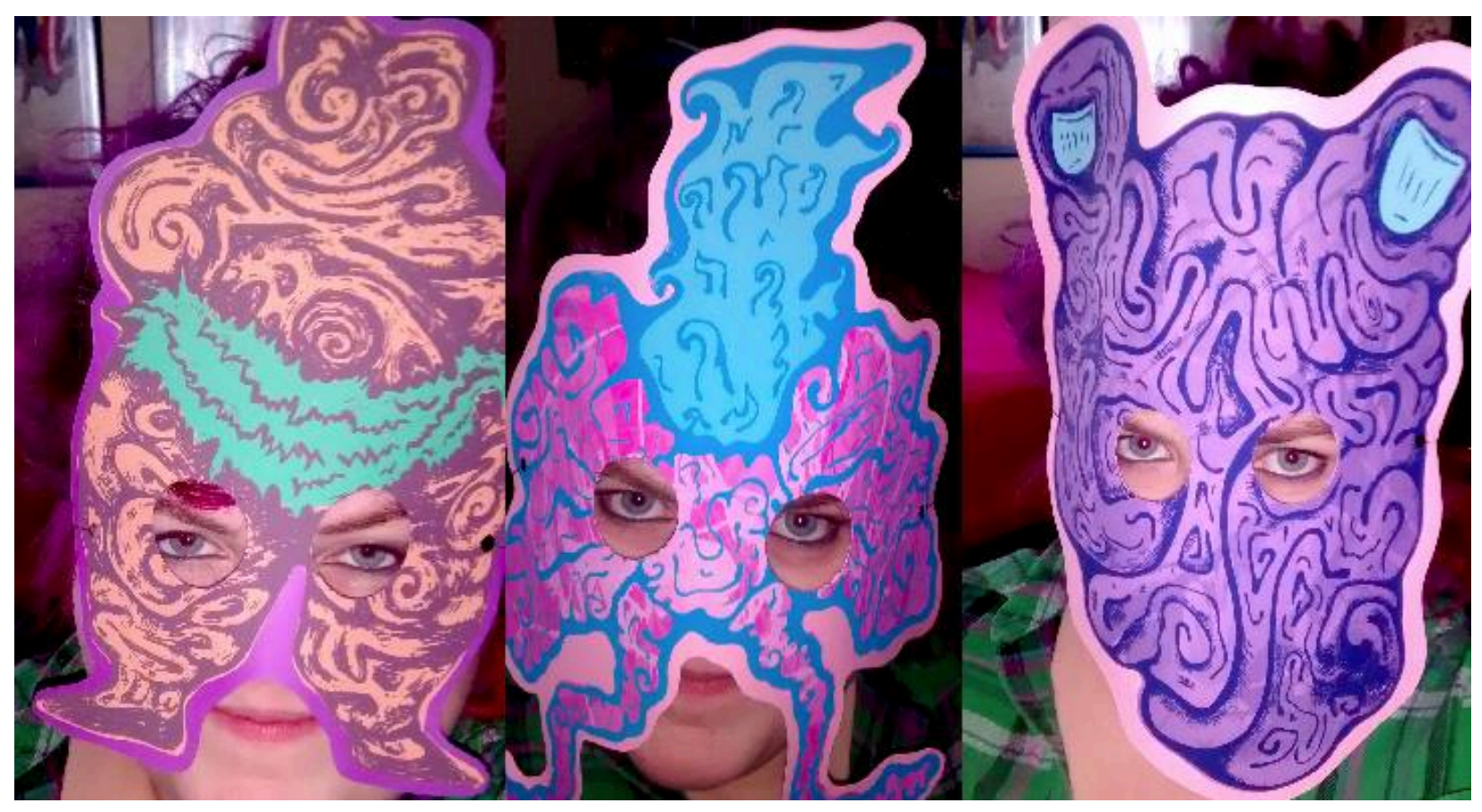

Fig.17 “Monster Masks”, silk-screen 


\section{BIBLIOGTAPHY}

Anderson, Hans Christian. "The Red Shoes." Hca.gilead.org. Last modified 2016. Accessed April 22,

2016.http://hca.gilead.org.il/red_shoe.html.

Bachlakova, Polina. "John Isaacs." helabmagazine.com. Last modified June 7, 2015. Accessed April 22,

2016. http://thelabmagazine.com/2015/06/07/john-isaacs/.

Beyer, Catherine. "Geometric Shapes - Triangles." About.com. Last modified 2016. Accessed April 22,

2016. http://altreligion.about.com/od/symbols/ig/Geometric-Shapes/Triangles.html.

Bolton, Andrew, Elvira Dyangani Ose, and Nato Thompson. Nick Cave: Epitome. New York, NY: PRESTEL,2014.

Britannica, Encyclopedia, ed."Polyphemus." Britannica.com. Last modified 2016. Accessed April 23,

2016. http://www.britannica.com/topic/Polyphemus-Greek- mythology.

Britannica, Encyclopedia, ed. "Pyramids of Giza -Khufu." Britannica.com. Last modified 2015. Accessed April

23, 2016. http://Brittannica.com/topic/pyramids-of-Giza.

"Cacomorphobia." Thefreedictionary.com. Last modified 2016. Accessed April 23, 2016. http://medical-dictionary.thefreedictionary.com/cacomorphobia.

Carlyon, David. The Education of a Circus Clown: Mentors, Audiences, Mistakes. Palgrave Studies in

Theatre and Performance History. New York, NY: Pallgrave Macmillan, 2016.

Cherry, Kendra. "The Five Levels of Maslow's Hierarchy of Needs."" Verywell.com. Last modified April

15, 2016. Accessed April 22, 2016. http://www.verywell.com/heirarchy-of-needs-795947.

"Chesterfields of England." Chesterfields.co.uk. Last modified 2015. Accessed April 22, 2016. http://www.chesterfields.co.uk.

"Cindy Sherman." Moma.org. Last modified 2012. Accessed April 23, 2016. http://Moma.org/interactives / exhibitions/2012/cindysherman/.

"Cirque du Soleil History." Cirquedusoleil.com. Last modified 2015. Accessed April 22, 2016. https://www.cirquedusoleil.com/en/press/kits/corporate/cirque-dusoleil/history.aspx. 
Cosgrove, Ben. "Ed Gein: Portrait of America's Original 'Psych Killer."' Times.com. Last modified March 31, 2014.

Accessed April 23, 2016. http://time.com/3879490/ed-gein-portrait-of-americas-originalpsycho-killer/.

Gnome Magazine. "Preparing For Performance Art With Marina Abramovic." Gnomemag.com. Accessed April

23, 2016. http://gnomemag.com/preparing-for-performance-art-with-marina-abramovic/.

Grundhauser, Eric. "The Dunce Cap Wasn't Always So Stupid." Atlasobscura.com. Last modified September

10, 2015. Accessed April 23, 2016. http://www.atlasobscura.com/articles/the-dunce-capwasnt-always-so-stupid.

Hoptman, Laura. "Yayoi Kusama's Return to Moma." Moma.org. Last modified October 9, 2012. Accessed

April 23, 2016. http://wwww.moma.org/explore/inside_out/2012/10/09/yayoi-kusamasreturn-to-moma/.

"Jessica Jackson Hutchins." Saatchigallery.com. Last modified 2016. Accessed April 23, 2016. http://www.saatchigallery.com/artists/jackson_hutchins.htm?section_name=paper.

Jones, David. Could You Ever Live Without? Colorado Springs, Co: Create Space Independent Publishing Platform, 2013.

Littleton, C. Scott. Mythology: The Illustrated Anthology of World Myth and Storytelling. London, UK: Duncan Baird, 2002.

Lorde, Audre, and Cheryl Clarke. Sister Outsider: Essays and Speeches. Crossing Press Feminist Series. N.p.:

Crossing Press, 2007.

"Mike Carey Quotes." Goodreads.com. Last modified 2016. Accessed April 23, 2016 https:// www. goodreads.com/author/quotes/9018.Mike_Carey.

Pan's Labyrinth. Directed by Guillermo Del Toro. 2007.

"Persephone." Greekmythology.com. Last modified 2016. Accessed April 23, 2016. http://www. greekmythology.com/Other_Gods/Persephone/persephone.html.

"Peter Paul Rubins 1577-1640." Nationalgallery.org.uk. Last modified 2016. Accessed April 23, 2016. https://www.nationalgallery.org.uk/artists/peter-paul-rubens. 
Pollock, Griselda, and Victoria Turvey-Sauron. The Sacred and the Feminine. New York, NY: Tauris \& Co, 2008.

"Quidam Cirque du Soleil." Topdocumentaryfilms.com. Last modified 2016. Accessed April 22, 2016. http://www.topdocumentaryfilms.com/ cirque- du-soleil-quidam/.

Schwartz, Alvin. Scary Stories To Tell In the Dark. Illustrated by Stephen Gammell. N.p.:

Scholastic, 1981.

Schwartz, Tracy. "How Oak Park Actor Became 'Buffalo Bill' in 'Silence of the

Lambs'." Chicagotribune.com. Last modified February 15, 2015. Accessed April 23,2016.

http://www.chicagotribune.com/entertainment/ct-silence- of-the-lambs-jame-gumb20160214-story.html.

Smith, Elizabeth, and Robert Storr. Lee Bontecour: A Retrospective of Sculpture and Drawing. New York, NY:

Henry N. Abrams Inc, 2003.

"Wide Load and Oversized Load Banner Requirements By State." US Cargo Control Blog. Entry posted

2014.Accessed April 23, 2016. http://Blog.uscargocontrol.com. 